\title{
Hydraulic resistances experimental and field studies of supply canals and pumping stations structures
}

\author{
Bakhtiyor Uralov ${ }^{1 *}$, Marina Li $^{1}$, Eshmatboy Qalqonov ${ }^{1}$, Zokhidjon Ishankulov ${ }^{2}$, Makhfuz \\ Akhmadi $^{1}$, and Lyudmila Maksudova ${ }^{1}$ \\ ${ }^{1}$ Tashkent Institute of Irrigation and Agricultural Mechanization Engineers, Tashkent, Uzbekistan \\ ${ }^{2}$ Andijan Institute of Agriculture and Agricultural Technologies, Andijan, Uzbekistan
}

\begin{abstract}
Currently, many authors have studied the uniform axisymmetric pressure head laminar and turbulent movement of water in hydraulic smooth and rough (with uniform roughness) pipes of circular cross-section. The results obtained in the study of a plane-parallel turbulent flow in pressure canals allows here only to outline the structure of the corresponding dependencies and to clarify the simplest case of unpressurized fluid movement, when this movement can also be reduced to plane-parallel or, in other words, to movement in a canal of infinitely large width with a flat bottom. In all other cases, the only way to solve the problem is an experiment. The construction of numerous free-flow watercourses and machine canals of pumping stations requires scientifically based calculation methods.
\end{abstract}

\section{Introduction}

At present, numerous pumping stations have been created in the irrigation systems of the Republic of Uzbekistan, with the help of which about 50 billion $\mathrm{m}^{3}$ of water are pumped per year for irrigation of more than 2 million hectares of irrigated land. The most important element of these pumping stations (PS) are water supply and water supply machine canals and structures of pumping stations (PS) [1-7]. Turning to the question of those engineering problems, in the solution of which the results of this work can be used, let us select, first of all, from the wide range of design cases related to free-flow canals, the main design case, which we will keep in mind in what follows (as, so to speak, "starting "). In most cases, the formulation of the above tasks boils down to the following - given: soil conditions and the amount of water flow. It is required to find such a slope of the water, at which the shape of its cross-section would be stable (i.e., indelible), and the area of the living section would be the smallest. It is known that such a problem, until recently, was solved by using the concept of "maximum permissible speed" $V_{\max }$, (referring to the uniform movement of water) [8-14]. The value of this speed was assigned (and is assigned at present) based on

${ }^{*}$ Corresponding author: vohidov.oybek@bk.ru 
reference data from the type of soil (and, in some cases, depending on the depth of water in the canal). Knowing Vmax and the flow rate, it is easy to find the cross-sectional area and the slope of the canal (using formulas to determine the Shezy coefficient $\mathrm{C}$ or the coefficient of hydraulic friction $\lambda$ and following the accepted value of the roughness coefficient 16, 22].

The object of research in operation is the Amu-Bukhara machine canal (ABMC), in the area of the damless water intake from the Amudarya river bed. Sections of the ABMC machine canals, from the head structure to the ABMC-1 and ABMC-2 pumping stations, were taken as the object of hydraulic research [17-21].

\section{Methods}

In the process of research, experimental methods, methods of field observation, as well as generally accepted methods in hydraulics, methods of compiling mathematical models based on the laws of hydromechanics, and their numerical calculations were used.

\section{Results and Discussion}

The results obtained in the study of a plane-parallel turbulent flow in pressure canals allows us to outline the structure of the corresponding dependencies and clarify the simplest case of unpressurized fluid movement, when this movement can also be reduced to planeparallel or, in other words, to movement in an infinitely large canal [22, 23, 26]. The results of studying the turbulent uniform free-flow movement of water in smooth canals obtained by various authors for the coefficient $\lambda_{R}$ in smooth gravity canals are similar in general form, which is obvious from (1):

$$
\frac{C}{\sqrt{2 g}}=\frac{1}{\sqrt{\lambda_{R}}}=a \lg \operatorname{Re}_{R} \sqrt{\lambda_{R}}+b_{r}=a \lg C_{r} \operatorname{Re}_{R} \sqrt{\lambda_{R}}
$$

And it differs only in the values of the constants $a, b_{r}, C_{r} . C$ decreasing constant $b_{r}$ in the formula (1) magnitude $\lambda_{R}$ increases. An extensive study of the turbulent movement of water in free-flow canals of rectangular cross-section with uneven-grained (sandy) artificial roughness of the surface of the bottom and walls of the canal was carried out by the author of the work A.P. Zegzhda. The results of this study led the author to an addiction graph:

$$
\lg \lambda_{R}=f\left(\lg \operatorname{Re}, \frac{R}{\Delta}\right)
$$

For the quadratic area of resistance, the author obtained the dependence:

$$
\frac{1}{\sqrt{\lambda_{R}}}=4 \lg \frac{R}{\Delta}+4.25=4 \lg 11.5
$$


Where $\Delta$ is absolute grain roughness (the diameter of the grains of sand, which were glued to the surface of the bottom and walls of the canal to create uneven grain roughness) Nikuradze for the area of quadratic resistance in pipes at one time received the dependence:

$$
\frac{1}{\sqrt{\lambda_{R}}}=4 \lg \frac{R}{\Delta}+4.68=4 \lg 14.8 \frac{R}{\Delta}
$$

The author of the work is A.P. Zegzhda, relying on the experimental data of Nikuradze, proposes a dependence of the form for free-flow flows:

$$
\frac{1}{\sqrt{\lambda_{R}}}=4 \lg \frac{R}{\Delta}+3.46=4 \lg 7.42 \frac{R}{\Delta}
$$

As you can see, the dependences obtained by various authors for the coefficient in free-flow canals with uniform artificial roughness have the form:

$$
\frac{C}{\sqrt{2 g}}=\frac{1}{\sqrt{\lambda_{R}}}=a \lg \frac{R}{\Delta}+b_{3}=a \lg c_{3} \frac{R}{\Delta}
$$

And differ in the values of the constants $a, b_{3}$, and $c_{3}$. Different values of the constant $a, b_{r}, c_{r}$ obtained in the works are due, from our point of view, mainly because these works do not fully take into account the effect on the size of the shape of the free cross-section of the canal $[24,25,27,28,29]$.

The results of experiments in experimental and field studies of hydraulic resistances of supplying machine canals and structures of pumping stations, the corresponding experiments are presented on models of free-flow canals of a rectangular and trapezoidal cross-section. And also, to fill the experimental data, the corresponding series of Bazin's experiments were used on models of free-flow canals - rectangular, trapezoidal, and semicircular cross-sections with different roughness. Canals with two types of the roughness of the bottom and wall surfaces were investigated: close to smooth (smooth concrete), and a surface with gravel glued on it $d=5-7 \mathrm{~mm}$.

In the above experimental canals of rectangular and trapezoidal cross-section, 4 series of experiments were combined. In each of them, 14 - 16 experimental points were filmed, with a constant slope of the canal bottom $i=0.001$. At the same time, 14-16 (usually 16) different flows were passed through the canal; they varied in the range from $4 \mathrm{l} / \mathrm{s}$ up to $250 \mathrm{l} / \mathrm{s}$. The Reynolds №s varied within $R e=6400+124000$, and the Froude №s $F r$ were $\mathrm{Fr}<1.0$. The hydraulic radius varied in each series of experiments in the range from 1.72 to $19.45 \mathrm{~cm}$. In each experiment, the flow rate, temperature, and flow depth were measured. In our case $(\mathrm{Fr}<1.0)$, in all experiments, the normal depth of a uniform flow was determined. In the dissertation work, the criteria for recalculating the results of experimental studies on nature are used. At the same time, the geometric dimensions of the experimental canal were recalculated based on the parameters of a real object, taking into account the scale of modeling. Based on experimental studies of the distribution of vertical velocities of the water flow, as well as field data of machine canals ABMC (water consumption in ABMC - $1 Q=75 \mathrm{m3} / \mathrm{s}$ and ABMC-2 is $Q=150 \mathrm{m3} / \mathrm{s}$ ) in nature, the water speed on the machine canal is quite high and is equal to $(v=3 \div 4,5 \mathrm{~m} / \mathrm{s})$, the obtained materials of experimental and natural conditions gave similar results [30-31]. 
In addition, the following series of Bazin's experiments were processed: Series № 2 (duct with rectangular cross-section: the surface of the bottom and walls of the canal is smooth cement; series № 24 (canal with a semicircular cross-sectional shape; the surface of the bottom and walls of the canal is smooth cement; series № 6 (canal with a rectangular cross-sectional shape; the surface of the bottom and walls of the canal are boards; series № 26 and series № 4 (canal with a rectangular cross-sectional shape; the surface of the bottom and walls of the canal - gravel $d=0.01-0.02$; series № 27 (the canal has a semicircular cross-sectional shape; the surface of the bottom and walls of the canal - gravel $d=0.01-$ $0.02 \mathrm{~m}$.

Determination of the coefficient of hydraulic friction $\Lambda$ and the Reynolds №, for all series of Bazin's experiments, was also carried out according to the usual dependencies. Further, according to the experimental data of our experiments and this series of Bazin's experiments, the heights of the roughness protrusions were determined $\Delta$, - for each defined hydraulic radius $R$, the opposite way at known values of the coefficient of hydraulic friction $\Lambda$. The results of the corresponding processing of the data of our series experiments № 1,3 , № 7,8 and Bazin's experiments series № 2, № 24, № 6, № 27, № 9, № 21 , № 23 figures 19.

At small values of the relative roughness, i.e., in the area of resistance close to smooth, the difference between $K$ for canals of a rectangular and semicircular cross-section is 12 $16 \%$, with an increase $\Delta / R$ relationship between $K$ increases to $32-44 \%$.

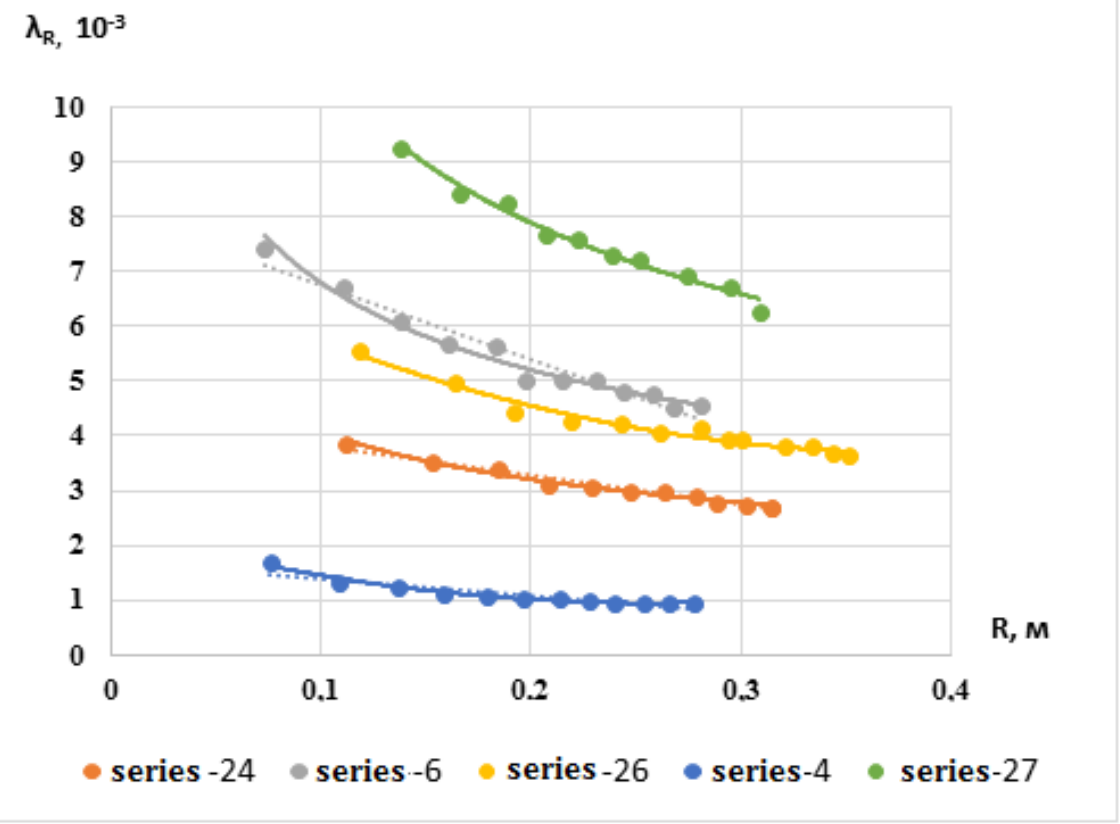

Fig. 1. Dependence $\lambda_{R}$ from $R$

Processing of Bazin's experiments and the author's experiments. 1 - Bazin's experiments, series № 24, semicircular canals, the surface of the bottom and walls of the canals - smooth concrete, series № 6, 26, rectangular and semicircular canals, the surface of the bottom and walls of the canals - boards, series № 4, 27, rectangular and semicircular canals, surface the bottom and walls of the canals - gravel $d=0.1-0.02 \mathrm{~m}$. 


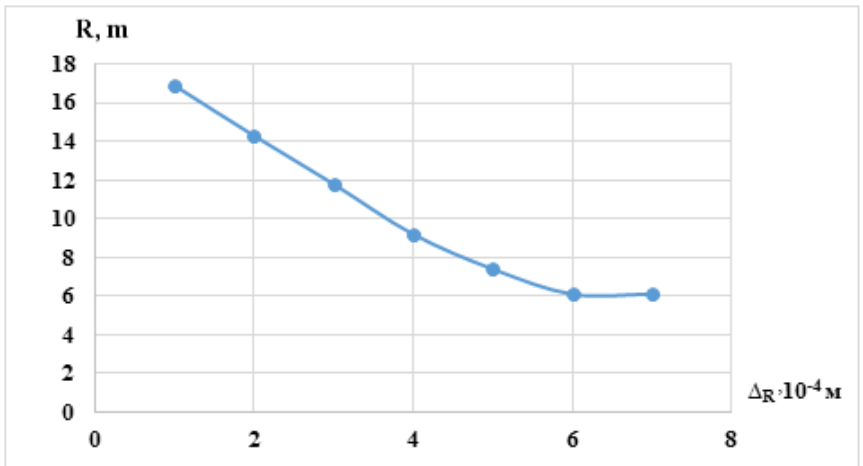

Fig. 2. Dependence $\Delta=f(R)$. The author's experiments, series № 9a; rectangular channel; the surface of the bottom and walls of the channel - iron; $B=0.23 \mathrm{~m}: i=2 \cdot 10^{-4} ; T=17.5^{0}$; $v=1.12 \cdot 10^{-6} \mathrm{~m}^{2} / \mathrm{s} ; \Delta \ni=11 \cdot 10^{-4} \mathrm{~m}$.
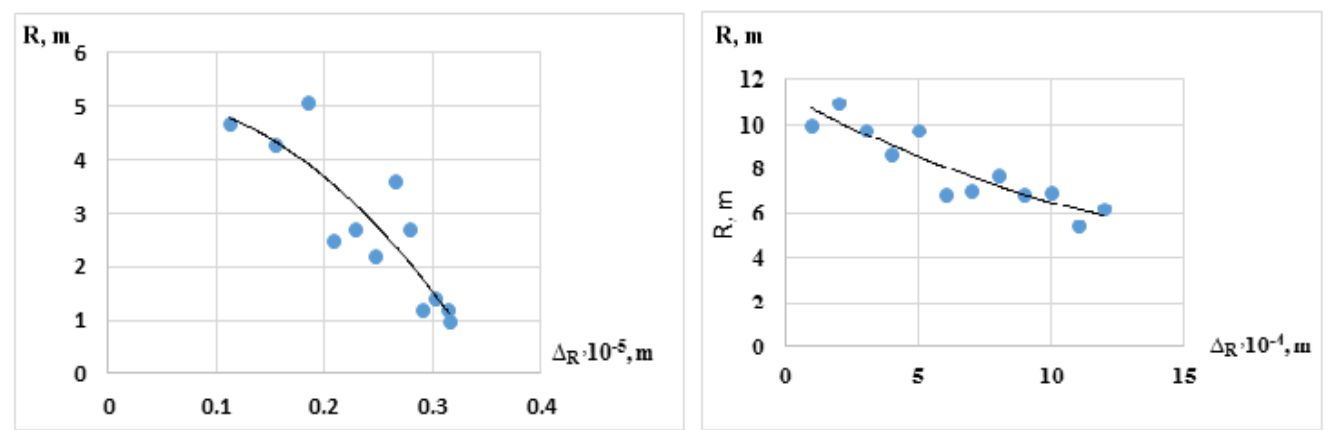

Bazin's experiments, series № 24; semicircular channel, bottom and wall surfaces-smooth concrete, $D=1.25 \mathrm{~m}, i=1.5 \cdot 10^{-3}$

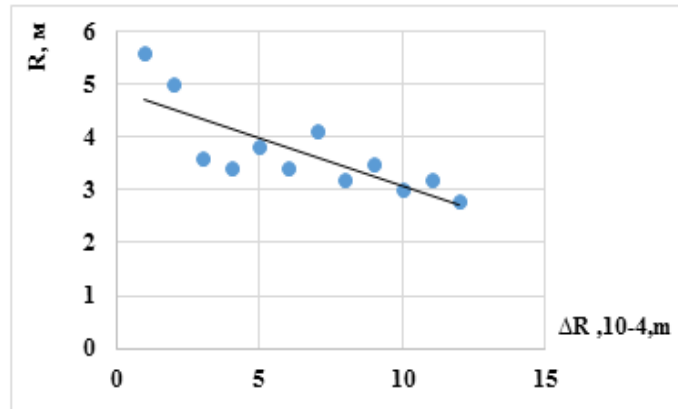

Processing of Bazin's experiments, series № 26

Processing of Bazin's experiments, series № 4
Bazin's experiments, series № 6, rectangular duct, bottom surface and walls - boards, $B=1.99 \mathrm{~m}, i=2.08 \cdot 10^{-3}$

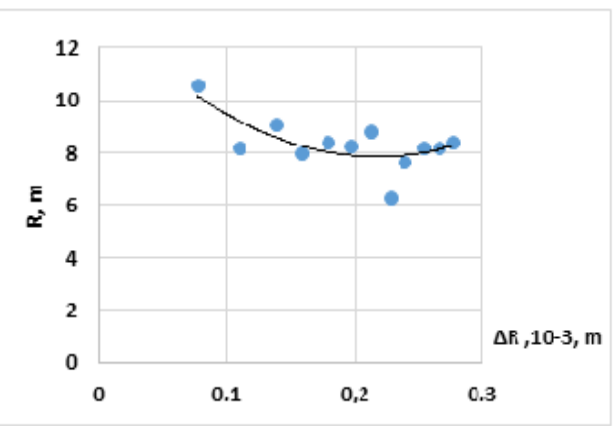

Fig. 3. Dependence $\Delta=f(R)$ 


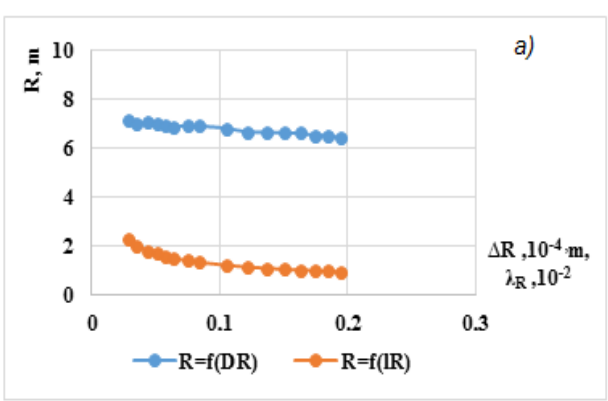

The author's experiments, series № 1; rectangular duct; channel bottom and walls - gravel; $d=$ $5-7 \mathrm{~mm} ; B=1.51 \mathrm{~m} ; i=1.0 \cdot 10^{-3} ; T=$ $19.4^{0} ; v=1.02 \cdot 10^{-6} \mathrm{~m} 2 / \mathrm{s}$;

Fig. 4. Dependence $\Delta=f(R)$ and $R=f(\lambda R)$.

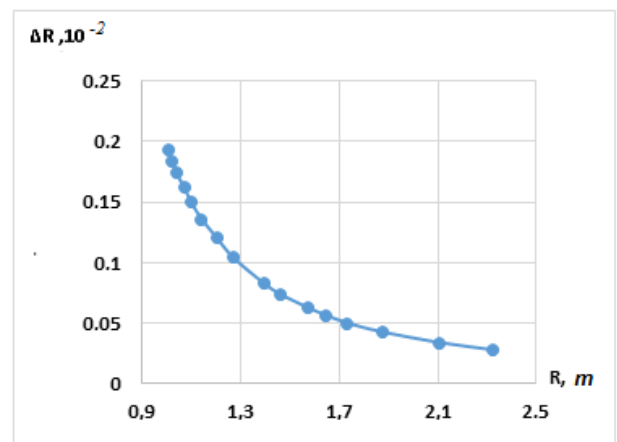

The author's experiments, series № 8; rectangular duct; channel bottom and walls - gravel; $d=5-7 \mathrm{~mm} ; B=1.51 ; i=1.0$. $10^{-3} ; T=19.4^{0} ; v=1.02 * 10^{-6} \mathrm{~m} 2 /$ $s ; \Delta \ni=7.4 \cdot 10^{-3} \mathrm{~m}$

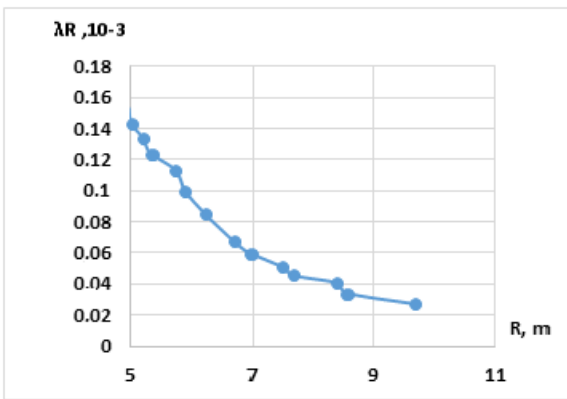

The author's experiments, series № 1; rectangular channel; the surface of the bottom and walls of the channel - smooth concrete; $B=1.51 \mathrm{~m} ; i=$ 1.0 $110^{-3} ; T=20^{0} ; v=1.0 \cdot 10^{-6} \mathrm{~m} 2 / \mathrm{s}$;

$\Delta \ni=7.0 \cdot 10^{-4} \mathrm{~m}$

Fig. 5. Dependence $R=f\left(\lambda_{R}\right)$ and $\Delta=f(R)$.

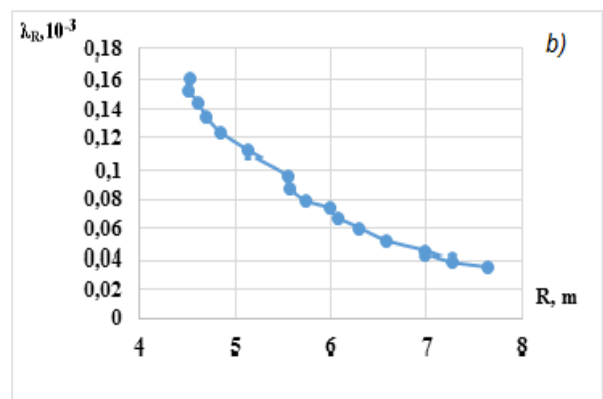

The author's experiments, series № 3; trapezoidal canal; the surface of the bottom and walls of the channel - smooth concrete; $b_{g}=0.16 \mathrm{~m} ; \mathrm{m}=$ 1,$732 ; i=1.0 \cdot 10^{-3} ; T=16.2^{0} ; v=1.1$. $10^{-6} \frac{\mathrm{m} 2}{\mathrm{~s}} ; \Delta_{\ni}=5.5 \cdot 10^{-4} \mathrm{~m}$

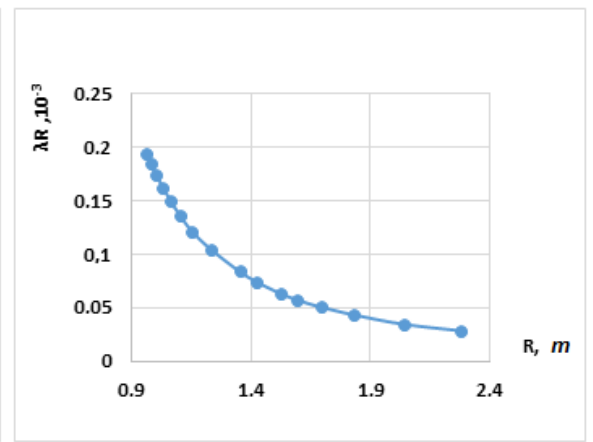

The author's experiments, series № 8; rectangular duct; the surface of the bottom and walls of the channel - gravel; $d=5-7 \mathrm{~mm} ; B=$ $1.51 ; i=1.0 * 10-3 ; T=19.4^{0} ; v=$ $1.02 \cdot 10^{-6} \mathrm{~m} 2 / \mathrm{s} ; \Delta \ni=7.4 \cdot 10^{-3} \mathrm{~m}$

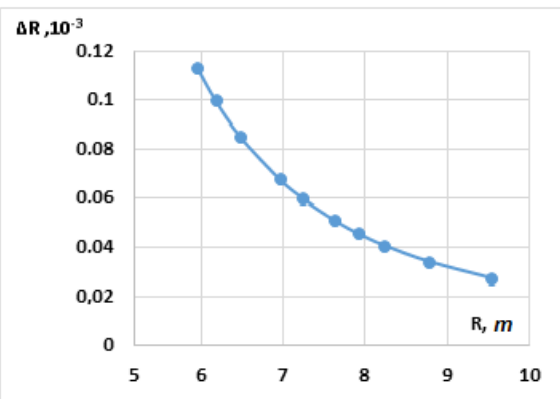

The author's experiments, series № 1; rectangular channel; the surface of the bottom and walls of the channel - smooth concrete; $B=1.51 \mathrm{~m} ; I=$ $1.0 \cdot 10^{-3} ; \quad T=20^{0} ; v=1.0 \cdot 10^{-6} \mathrm{~m} 2 / \mathrm{s}$; $\Delta \ni=7.0 \cdot 10^{-4} \mathrm{~m}$ 


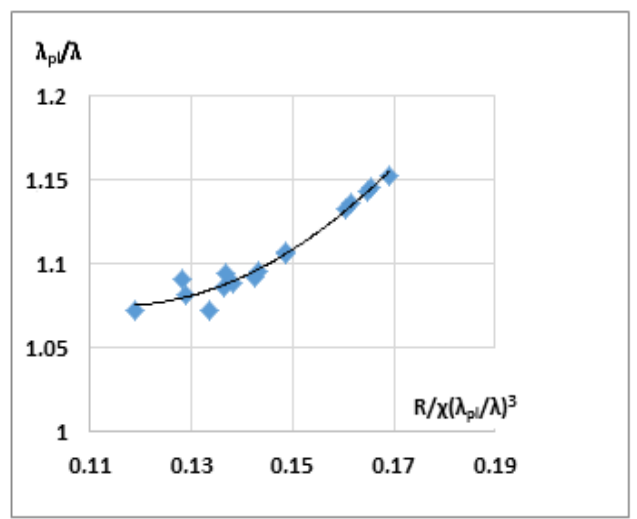

The author's experiments, series № 3; trapezoidal canal; the surface of the bottom and walls of the channel - smooth concrete; $b_{g}=$ $0.16 \mathrm{~m} ; \mathrm{m}=1.732 ; i=1.0 \cdot 10^{-3} ; T=16.2^{0}$; $v=1.1 \cdot 10^{-6} \mathrm{~m} 2 / \mathrm{s} ; \Delta \ni=5.5 \cdot 10-4 \mathrm{~m}$

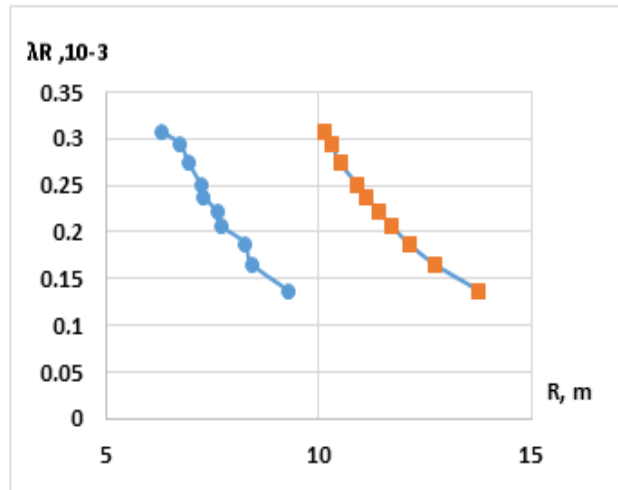

Bazin's experiments, series № 27; semicircular canal; the surface of the bottom and walls of the channel - gravel; $d=0.01-0.02 \mathrm{~m}: D=1.22$ $m ; i=1.510-3 ; T=12^{0} ; v=1.23 \cdot 10^{-6} \mathrm{~m} 2 / \mathrm{s}$; $\Delta \ni=12 \cdot 10^{-3} \mathrm{~m}$

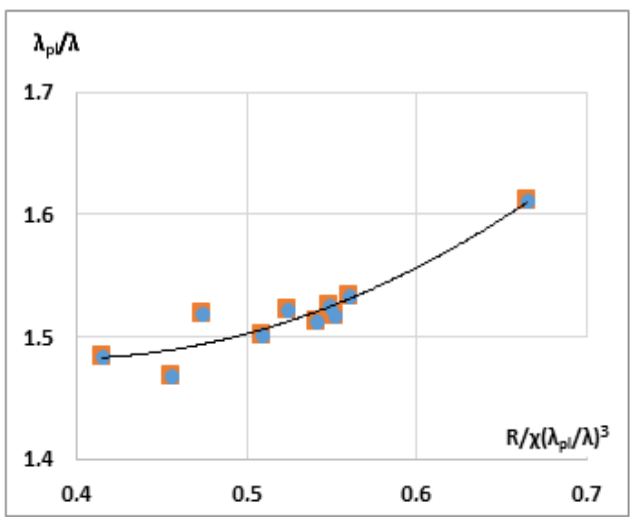

Bazin's experiments, series № 27; semicircular canal; channel bottom and walls - gravel; $d=0,01$ $0.02 \mathrm{~m}: D=1.22 \mathrm{~m} ; i=1.510-3 ; T=12^{\circ}$; $v=1.23 \cdot 10^{-6} \mathrm{~m} 2 / \mathrm{s} ; \Delta \ni=12 \cdot 10^{-3} \mathrm{~m}$

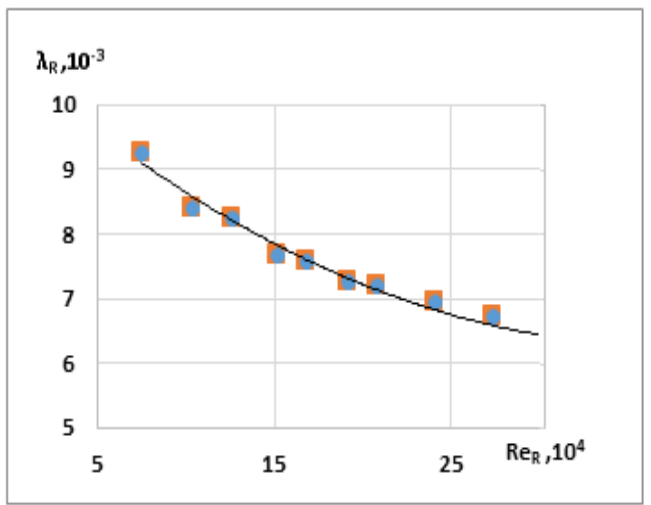

Bazin's experiments, series № 27; semicircular canal; the surface of the bottom and walls of the channel - gravel; $d=0,01-0,02 \mathrm{~m}: D=1,22 \mathrm{~m}$; $i=1.5 \cdot 10^{-3} ; T=12^{0} ; v=1.23 \cdot 10^{-6} \mathrm{~m} 2 / \mathrm{s}$; $\Delta \ni=12 \cdot 10^{-3} \mathrm{~m}$ 


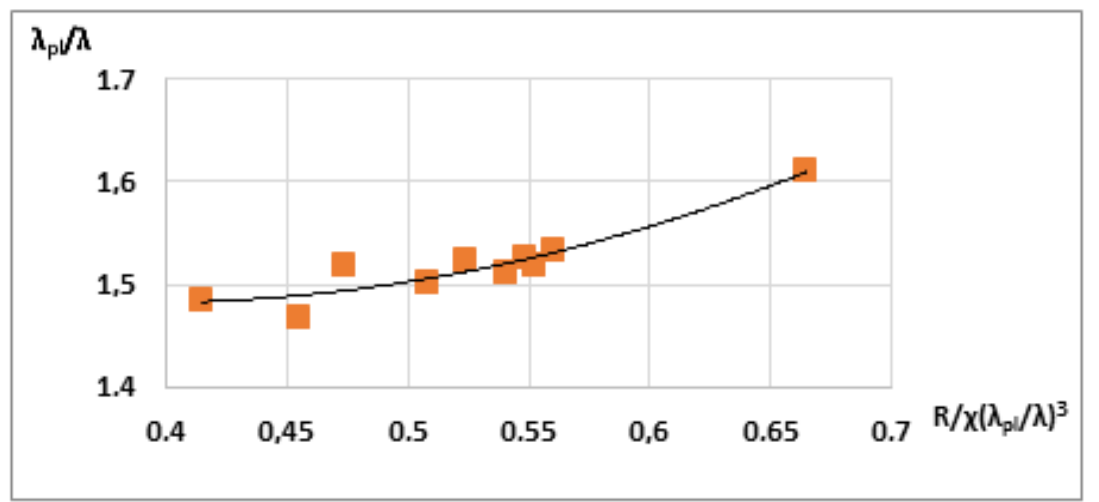

Bazin's experiments, series № 27; semicircular canal; the surface of the bottom and walls of the channel - gravel; $d=0.01-0.02 \mathrm{~m}: D=1.22 \mathrm{~m} ; i=1.5 \cdot 10-3 ; T=12^{0} ; v=1.23 \cdot 10^{-6} \mathrm{~m} 2 / \mathrm{s}$;

$\Delta{ }=12 \cdot 10^{-6} \mathrm{~m}$

Fig. 6. Dependence $\frac{\lambda_{p l}}{\lambda}=f\left[R / \chi\left(\frac{\lambda_{p l}}{\lambda}\right)^{3}\right]$

Bazin's experimental data in canals with regular cross-sections of various geometric shapes (rectangular, trapezoidal, triangular, semicircular), as well as experimental data on the flow in rectangular and trapezoidal canals obtained in this work; the results of some published data on water flows in canals of various geometric shapes were summarized on the graph below in coordinates $\left[R / \chi\left(\lambda_{p l} / \lambda\right)^{3} ; \lambda_{p l} / \lambda\right]$, (figure $4-9$ ).

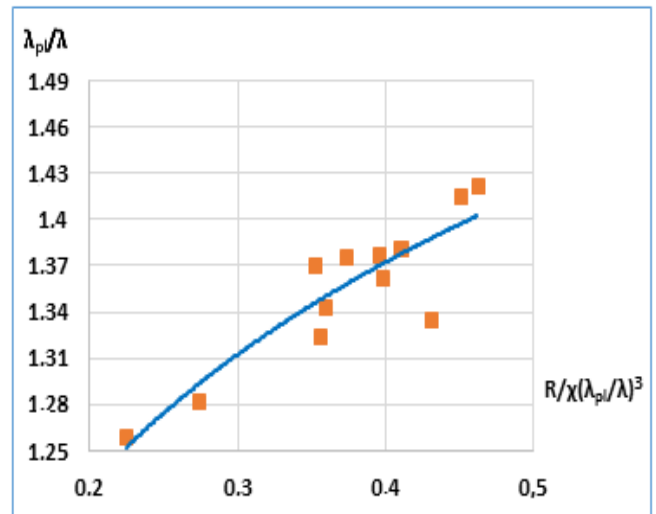

Bazin's experiments, series № 26; semicircular canal; the surface of the bottom and walls of the channel - boards; water temperature: $T=18^{\circ}$ in experiments № $1-12: v=1.06 \cdot 10^{-3}$; and $T=22.5^{0}$ in № 13; $v=0.95 \cdot 10^{-6} \mathrm{~m} 2 / \mathrm{s} ; \Delta \ni=1410^{-4} \mathrm{~m}$

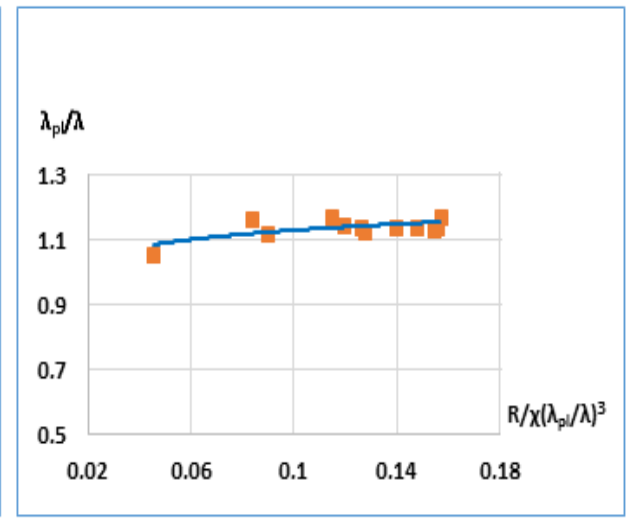

Bazin's experiments, series № 4; rectangular duct; channel bottom and walls- gravel; $d=0.01$ $0.02 \mathrm{sm}: B=1.832 \mathrm{~m} ; i=4.910^{-3} ; T=4.5^{0} ; v=$ $1.52 \cdot 10 \mathrm{~m} 2 / \mathrm{s} ; \Delta \ni=12 * 10^{-3} \mathrm{~m}$ 


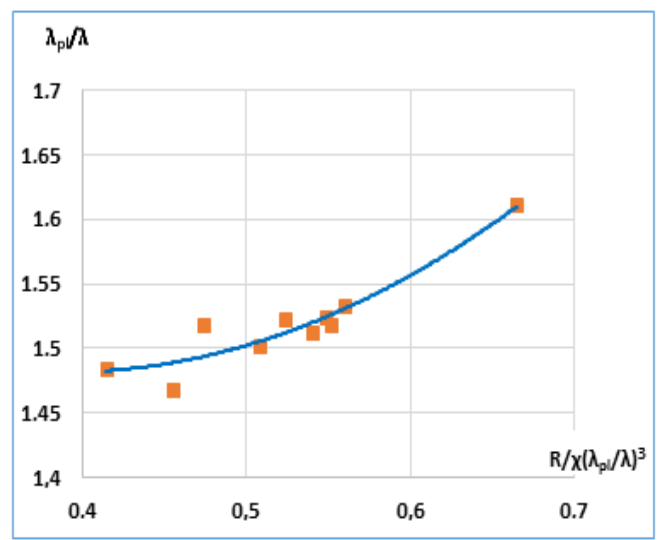

Bazin's experiments, series № 27; semicircular canal; the surface of the bottom and walls of the channel - gravel; $d=0.01-0.02 \mathrm{~m}: D=1.22 \mathrm{~m}$; $i=1.510^{-3} ; T=12^{0} ; v=1.23,10^{-6} \mathrm{~m} 2 / \mathrm{s}$; $\Delta \ni=12 \cdot 10^{-3} \mathrm{~m}$

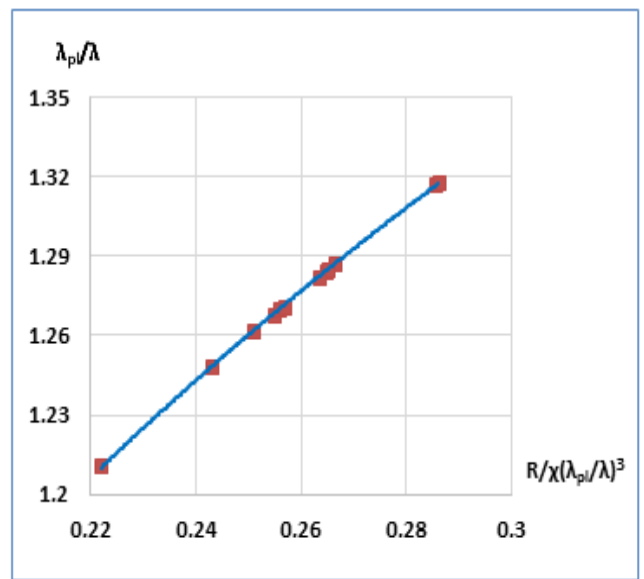

Bazin's experiments, series 9b; rectangular duct; the surface of the bottom and walls of the channel-boards; $B=1.23 \mathrm{~m}: i=1.5 \cdot 10^{-3}, T=17.5^{\circ}$; $v=1.15 \cdot 10-6 \mathrm{~m} 2 / \mathrm{s} ; \Delta{ }=14 \cdot 10^{-4} \mathrm{~m}$

Fig. 7. Dependence $\frac{\lambda p l}{\lambda}=f\left[R / \chi\left(\frac{\lambda_{p l}}{\lambda}\right)^{3}\right]$

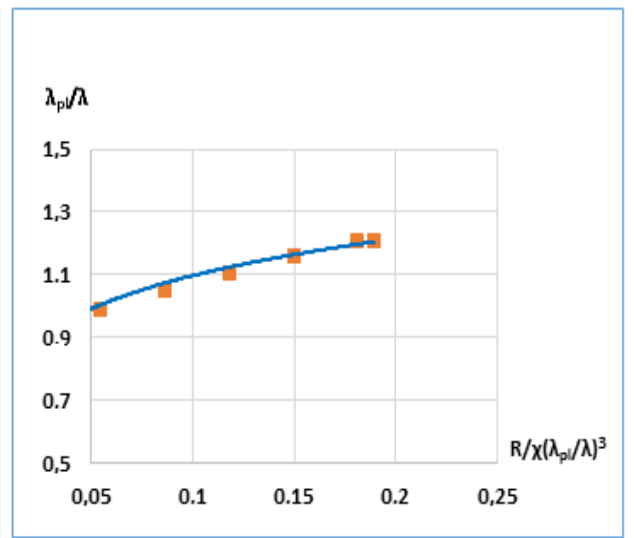

Bazin's experiments, series № 9a; rectangular duct; the surface of the bottom and walls of the channel- boards; $B=1,983 \mathrm{~m}: i=1.5 \cdot 10^{-3}$; $T=14.5^{0} ; v=1.15 \cdot 10^{-6} \mathrm{~m} 2 / \mathrm{s} ; \Delta \ni=1410^{-4} \mathrm{~m}$

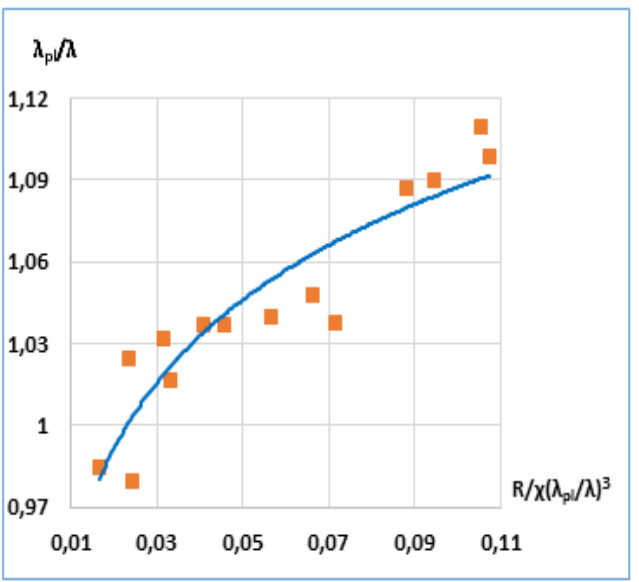

The author's experiments, series № 1, rectangular channel; the surface of the bottom and walls of the channel - smooth concrete; $B=1.51 \mathrm{~m}$; $i=\cdot 10^{-3} ; T=20^{0} ; v=10^{-6} \mathrm{~m} 2 / \mathrm{s} ; \Delta \ni=7.010^{-4} \mathrm{~m}$ 


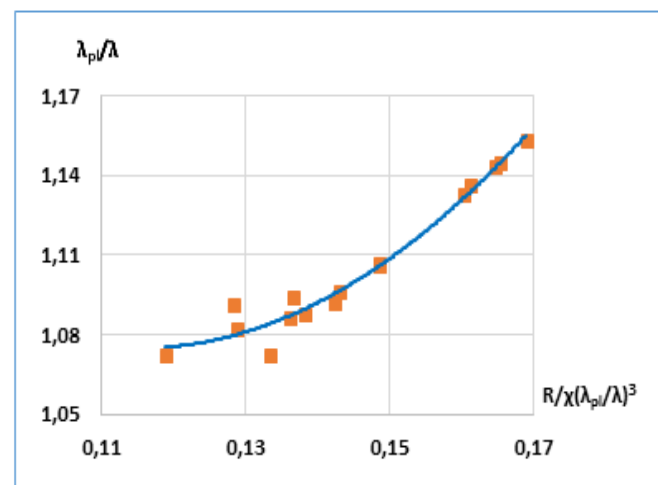

The author's experiments, series № 3; trapezoidal canal; the surface of the bottom and walls of the channel - smooth concrete; $b_{g}=0.16 \mathrm{~m} ; \mathrm{m}=1.732$; $i=1.0 \cdot 10-3 ; T=16,2^{0} ; v=1.1 \cdot 10^{-6} \mathrm{~m} 2 / \mathrm{s}$; $\Delta \ni=5.5 \cdot 10^{-4} \mathrm{~m}$

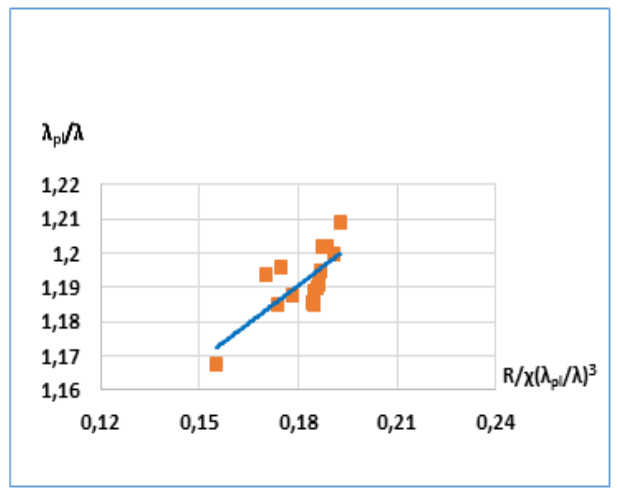

The author's experiments, series № 7; trapezoidal canal; the surface of the bottom and walls of the channel - gravel; $d=5-7 \mathrm{~mm} ; b_{g}=0.16 \mathrm{~m}$; $m=1.732 ; i=\cdot 10^{-3} ; T=16.2^{0} ; v=1.1 \cdot 10-6 \mathrm{~m} 2 / \mathrm{s}$; $\Delta \ni=5.810^{-3} \mathrm{~m}$

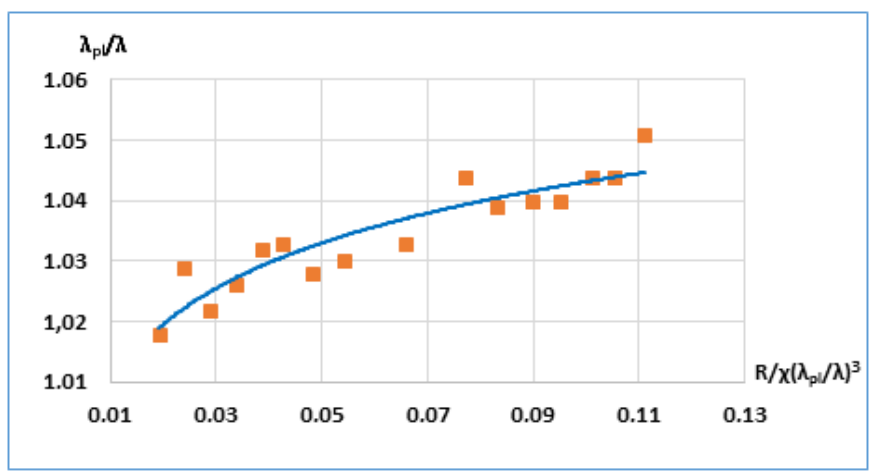

The author's experiments, series № 8 ; rectangular duct; the surface of the bottom and walls of the channel - gravel; $d=5-7 \mathrm{~mm} ; B=1.51 ; i=10^{-3} ; T^{0}=19.4^{0} ; v=1.02 \cdot 10^{-6} \mathrm{~m} 2 / \mathrm{s} ; \Delta \ni=7.4 \cdot 10^{-3} \mathrm{~m}$ Fig. 8. Dependence $\frac{\lambda_{p l}}{\lambda}=f\left[R / \chi\left(\frac{\lambda_{p l}}{\lambda}\right)^{3}\right]$

Bazin's experimental data in canals with regular cross-sections of various geometric shapes (rectangular, trapezoidal, triangular, semicircular), as well as experimental data on the flow in rectangular and trapezoidal canals obtained in this work; the results of some published data on water flows in canals of various geometric shapes were summarized on the graph below in coordinates $\left[R / \chi\left(\lambda_{p l} / \lambda\right)^{3} ; \lambda_{p l} / \lambda\right]$ (figure 8). 


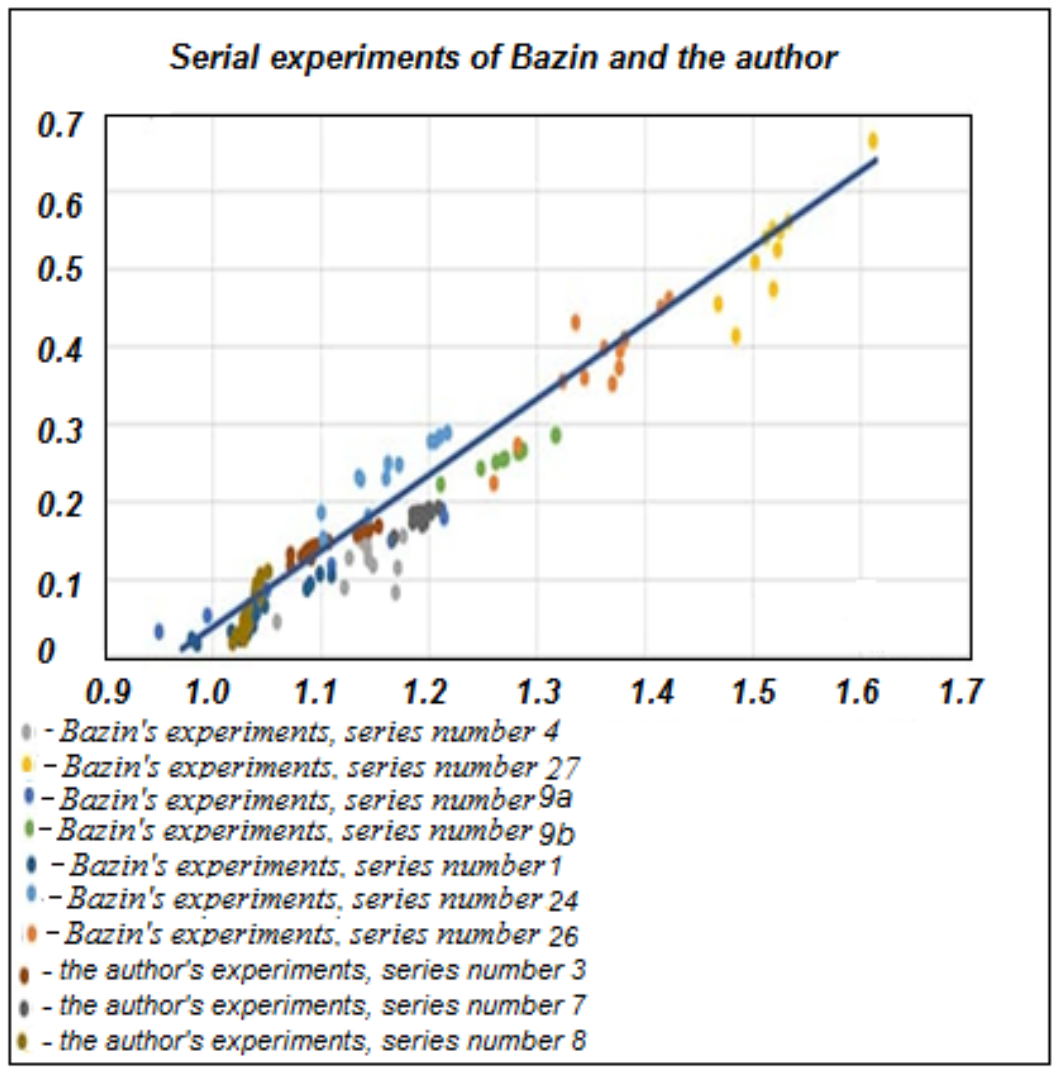

Fig. 9. Dependence $\frac{\lambda_{p l}}{\lambda}=f\left[R / \chi\left(\frac{\lambda p l}{\lambda}\right)^{3}\right]$

On the indicated chart (see figure 9), points corresponding to Bazin's experimental data. L.I. Neronova. Yu.P. Titov, N.D. Kasyanova and the author of this work are quite well located near the straight line, which has an equation of the form:

$$
\begin{aligned}
& \frac{\lambda_{p l}}{\lambda}=R / \chi\left(\frac{\lambda_{p l}}{\lambda}\right)^{3}+1.0 \\
& \lambda^{3}-\lambda_{p l} \lambda^{2}+R / \chi \cdot \lambda_{p l}^{3}=0
\end{aligned}
$$

Whence for the quantity $\lambda$ the following cubic equation is obtained where,

$\lambda$ is desired coefficient of hydraulic friction; $\lambda n \pi$ is flat flow hydraulic friction coefficient; $R$ is hydraulic radius; $\chi$ is wetted perimeter. Equation (9) can be resolved for the quantity at known values $\lambda n \pi . R$ and $\chi$.

Equation discriminant (9) reduced to form $y^{3}+3 p g+2 q=0$, Where $y=\lambda-\lambda_{p l} / 3$ vanishes at $R / \chi=4 / 27$. When $R / \chi>4 / 27$ the discriminant is greater than zero and the cubic equation has one real solution: 


$$
\lambda=\lambda_{p l}\left[\begin{array}{l}
\sqrt[3]{\sqrt{\frac{1}{4}\left(\frac{R}{\chi}-\frac{2}{27}\right)^{2}-\frac{1}{9^{3}}-\frac{1}{2}\left(\frac{R}{\chi}-\frac{2}{27}\right)}} \\
-\sqrt[3]{\sqrt{\frac{1}{4}\left(\frac{R}{\chi}-\frac{2}{27}\right)^{2}}-\frac{1}{9^{3}}+\frac{1}{2}\left(\frac{R}{\chi}-\frac{2}{27}\right)}
\end{array}\right]
$$

When $R / \chi<4 / 27$ discriminant less than or equal to zero. In this case, equation (9) has three real solutions, of which (as shown by the analysis), only a solution of the form satisfies the conditions of the problem under consideration:

$$
\lambda=\frac{\lambda_{p l}}{3}\left\{1+2 \cos \left[\frac{\arccos \left(1-\frac{27}{2} R / \chi\right)}{3}\right]\right\}
$$

From the above, the following procedure for calculating the coefficient of hydraulic friction follows $\lambda$ for free-flow ducts of the correct cross-section. The following canal data is assumed to be known; cross-sectional dimensions (bottom width, slope ratio, etc.), type of roughness (uneven-grained, not uneven-grained) and the equivalent absolute height of the roughness protrusions of the wetted surface $\Delta \ni$; slope I, canal filling depth $h$ and, therefore, the quantity $R / \chi$. The sought values are; hydraulic friction coefficient $\lambda$, average flow rate $\vartheta$, water consumption $Q$. The values are calculated; $\omega \cdot \chi \cdot R \cdot v_{*}=\sqrt{g R i} * \Delta=\Delta \ni / \mathrm{h}$; from the law of resistance for an infinite wide (flat) canal, for example, with a non-unequal roughness of the wetted surface:

$$
1 / \sqrt{\lambda n л}=4.06 \lg \left[11.03 /\left(\frac{3,3}{\mathrm{Re}_{h}^{*}}+\frac{\Delta_{0}}{h}\right)\right]
$$

(Where, $\mathrm{Re}^{*}{ }_{\mathrm{h}}=\mathrm{v}^{*} \mathrm{~h} / \mathrm{v}: \mathrm{v}^{*}$ - dynamic flow velocity), the value is calculated $\lambda n \pi$ for flat flow with depth $h$. Of given formulas for the solution of cubic equation (9) following the given value $R / \chi$, the required value is found $\lambda$.

\section{Conclusions}

1. Experimental data published in the literature on pressure losses in free-flow canals with a "regular" cross-section, as well as the data of our studies, as well as studies of other authors, show that the value of pressure losses in the above canals is not only a function of the Reynolds №, but also a significant degree (especially in canals with a rough wetted surface) depends on the shape of their cross-section.

2. From consideration of the collected experimental data on losses in the abovementioned free-flow canals, it follows that for several canals with different cross-sectional shapes but with the same slopes and the same roughness of the wetted surface, the curves on the graph $\left(\operatorname{Re}_{R}=\vartheta R / v, \lambda_{R}=2 \vartheta_{*}^{2} / \vartheta^{2}\right.$ ) will be arranged in the following order (from top to bottom); a very wide rectangular canal, a relatively narrow rectangular canal, trapezoidal and triangular canals, a semicircular cross-section canal. 
3. The value of the coefficient of hydraulic friction $\lambda_{R}$ for a very wide canal or canal of rectangular cross-section, all other things being equal, it has more effect than for a canal of a trapezoidal or semicircular cross-section. Corresponding dependence curves $\lambda_{R}$ of the № $R e_{R}$ at the same time pass approximately parallel to the curve obtained for the law of "smooth resistance."

4. In the area of the supply canal, intense deformations of the Amudarya river canal occur and, according to the calculations, the volume of siltation is $13-15$ million $\mathrm{m}^{3}$, of which up to $10 \%$ of this value is formed due to a decrease in the transporting capacity of the flow in the supply canal of pumping stations AB-1 and AB-2 (ABMC).

5. Taking into account (according to the recommended dependencies) the effects of the cross-sectional shape and roughness on the value of pressure losses in the free-flow machine canals of pumping stations, of the correct shape can give a significant economic effect on their design.

\section{References}

1. Zegzhda A.P. Gidravlicheskiye poteri na treniye v kanalakh i truboprovodakh. Gos. Izdatel'stvo literatury po stroitel'stvu i arkhitekture, pp.277, Moscow, (1957)

2. Wagner H. Beitrag zur Abflusberechnung offener Gerinne. Wissensehaftlicha Zoitschrift der Technischen Univeraitat Dresden, № 3, pp. 641-648, (1972)

3. Kartvelishvili N.A. Potoki v nedeformiruyemykh ruslakh, p. 280, Leningrad, (1973)

4. Shaazizov F.,Uralov B., Shukurov E., Nasrulin A. Development of the computerized decision-making support system for the prevention and revealing of dangerous zones of flooding, XXII international Scientific Conference on Advanced in Civil Engineering, E3S Web of Conferences 97, p. 05040 (2019)

5. M.Mamajonov, D.R.Bazarov, B.R.Uralov, G.U.Djumabaeva, N.Rahmatov. The impact of hydro-wear parts of pumps for operational efficiency of the pumping station, Journal of Physics: Conference Sereis. J.Phys.Conf.ser., 1425 (2020) doi:10.1088/1742-6596/1425/1/012123

6. Bazarov D., Uralov B., Matyakubov B., Vokhidov O., Uljaev F., M. Akhmadi. The effects of morphometric elements of the canal on hydraulic resistance of machine canals of pumping stations, IOP Conf. Series: Materials Science and Engineering, $869,(2020)$

7. Uralov B., Xidirov S., Matyakubov B., Eshonkulov Z., Norkulov B., Gayur A. River canal deformations in the area of damless water Intake. IOP Conf. Ser.: Mater. Sci. Eng. 869, (2020), doi:10.1088/1757899 X/869/7/072014

8. Uralov B., Saidkhodjaeva D., Kurbonova U. and Baymanov R. Influence of the shape of the pressureless trapezoidal canal and roughness on the pressure loss of the machine canals of the pumping stations, IOP Conf. Ser.: Mater. Sci. Eng. 883, (2020), doi:10.1088/1757899X/883/1/012012

9. Uralov B., Isabaev K., Jamolov F., Akhmadi M. and Mirzaev M. The influence of the shape the living section of the pressureless machine canal and the roughness of its wetted surface on the hydraulic resistance, IOP Conf. Ser.: Mater. Sci. Eng. 883, IOP Conf. Series: Materials Science and Engineering 883 (2020), doi:10.1088/1757899X/883/1/012006

10. Keulegan G.H. And Patterson G.W. Effect of turbulence and canal slope on traneletion waves. Journal of Research of the Hational Bureau of Standards, 30, pp. 462-512, (1943) 
11. Neronova L.P., Titov Y.P. Zakonomernosti gidravlicheskikh soprotivleniy $\mathrm{v}$ pryamougol'nykh ruslakh razlichnoy shiriny, Sb. nauch. Trudov-Gidravlika i gidrotekhnika, 22, pp.17-21, (1976)

12. Krutov A., Choriev R., Norkulov B., Mavlyanova D. and Shomurodov A. Mathematical modelling of bottom deformations in the kinematic wave approximation. IOP Conf. Ser. Mater. Sci. Eng. 1030, 012147 (2021).

13. Uralov B., Rakhmatov N., Khidirov S., Safarov G., Uljaev F., and Raimova I. Hydraulic modes of damless water intake, IOP Conf. Series: Materials Science and Engineering 1030, (2021), doi: 10.1088/1757-899X/1030/1/0121231

14. Krutov A., Norkulov B., Uljaev F., and Jamalov F. Results of a numerical study of currents in the vicinity of a damless water intake. IOP Conf. Ser. Mater. Sci. Eng. 1030, 012121 (2021).

15. Uralov B., Choriev R., Maksudova L., Sapaeva M., Shernaev A., and Nurmatov P. Substantiation of the influence of the canal shape and the roughness of machine canals on the pressure loss of irrigation pumping stations. IOP Conf. Series: Materials Science and Engineering 1030 (2021), doi: 10.1088/1757-899X/1030/1/012148

16. Bazarov D., Vatin N., Obidov B., and Vokhidov O. Hydrodynamic effects of the flow on the slab of the stand in the presence of cavitation. IOP Conf. Ser. Mater. Sci. Eng. 1030, 012110 (2021).

17.

18. Bazarov D., Markova I., Norkulov B. and Vokhidov O. Hydraulic aspects of the layout of head structures during water intake from lowland rivers. IOP Conf. Ser. Mater. Sci. Eng. 1015, 012041 (2021).

19. Bazarov D., Markova I., Sultanov S. and Kattakulov F. Dynamics of the hydraulic and alluvial regime of the lower reaches of the Amudarya after the commissioning of the Takhiatash and Tuyamuyun hydrosystems. IOP Conf. Ser. Mater. Sci. Eng. 1030, 012110 (2021).

20. Krutov A., Norkulov B., Mavlyanova D. Simulation of spreading of non-conservative passive substances in water bodies. IOP Conf. Ser. Mater. Sci. Eng. 883(1), 012028 (2020)

21. Bazarov D. and Vokhidov O. Extinguishing Excess Flow Energy in Spillway Structures. In book: Proceedings of EECE 2020, LNCE 150, pp. 535-545, (2021) DOI: 10.1007/978-3-030-72404-7_52

22. Rybakov V., Jos V., Raimova I., and Kudryavtsev K. Modal analysis of frameless arches made of thin-walled steel profiles. IOP Conf. Ser. Mater. Sci. Eng. 883, (2020).

23. Bazarov D., Markova I., Norkulov B., Isabaev K., Sapaeva M. Operational efficiency of water damless intake. IOP Conf. Ser. Mater. Sci. Eng. 869(7), 072051, (2020)

24. Obidov B., Vokhidov O., Tadjieva D., Kurbanova, U., Isakov A. Hydrodynamic effects on the flow elements of the downstream devices in the presence of cavitation. IOP Conf. Ser. Mater. Sci. Eng. 1030, 012114 (2021).

25. Bazarov D., Norkulov B., Vokhidov O., Uljaev F., Ishankulov, Z. Two-dimensional flow movement in the area of protective regulatory structures. IOP Conf. Ser. Mater. Sci. Eng. 890, 012162 (2020)

26. Matyakubov B., Begmatov I., Raimova I. and Teplova G. Factors for the efficient use of water distribution facilities. IOP Conf. Ser. Mater. Sci. Eng. 883, 012025 (2020).

27. Krutov A., Norkulov B., Nurmatov P., Mirzaev M. Applicability of zero-dimensional equations to forecast nonconservative components concentration in water bodies. IOP Conf. Ser. Mater. Sci. Eng. 883(1), 012028 (2020) 
28. Krutov A., Norkulov B., Nurmatov P., Mirzaev M. Applicability of zero-dimensional equations to forecast nonconservative components concentration in water bodies. IOP Conf. Ser. Mater. Sci. Eng. 883(1), 012028 (2020)

29. Krutov A., Norkulov B., Artikbekova F., Nurmatov P. Optimal location of an intake at a reservoir prone to salt diffusion. IOP Conf. Ser. Mater. Sci. Eng. 869(7), 072020, (2020)

30. Shokirov B., Norkulov B., Nishanbaev Kh., Khurazbaev M., Nazarov B. Computer simulation of channel processes. E3S Web of Conferences, 97, 05012, (2019)

31. Bazarov D., Markova I., Raimova I., Sultanov Sh. Water flow motion in the vehicle of main channels. IOP Conf. Ser. Mater. Sci. Eng. 883, 012025 (2020).

32. Shomayramov, M., Norkulov B., Rakhmanov J., Tadjiyeva D., Suyunov J. Experimental researches of hydraulic vacuum breakdown devices of siphon outlets of pumping stations. E3S Web of Conferences, 97, 05009, (2019) 